\title{
Research on Energy-saving of Adjustable Ventilation Platform Doors System in subway
}

\author{
Yue Zhang ${ }^{1}$, Xiaofeng $\mathrm{Li}^{1}$, Bin Wang ${ }^{2}$ \\ ${ }^{1}$ Department of Building Science, Tsinghua University, Beijing, China \\ ${ }^{2}$ Wuxi Metro Co. Ltd., Wuxi, China
}

\begin{abstract}
The adjustable ventilation platform doors system in subway combines the advantages of platform-screendoors system and the platform-bailout-door system, in result, shows energy saving effect in HVAC system. This research paper studied the ventilation effect by network simulation method using STESS software. Based on the ventilation simulation results, the energy saving effect of the system was analysed.

The study objective is subway, which can be transformed into a network airflow model based on hydromechanics principles and subway structures. Thus, network simulation was applied in the subway ventilation research. Based on modelling, the relationship between ventilation volume and open area was found and discussed, which has never be down before. Moreover, the simulation results enable further analysis on energy consumption of subway HVAC system.
\end{abstract}

\section{Introduction}

Nowadays, most of the subway stations apply the platform door system. There are two main categories of platform doors, the platform screen door (PSD) and the platform bailout door (PBD). The major difference between them is whether the platform door separates the platform and tunnel areas completely. These two forms have their pros and cons.

In summer, the PSD system can reduce the air exchange among outdoor space, tunnel area and platform area due to its sailing feature. In this way, the cooling load reduces and thus leading to the energy saving effect of HVAC system in subway station. In transition seasons such as spring and autumn, the PBD system is able to take advantage of the air exchange caused by piston effect (Chen et al, 1998; Cross et al, 2017; Kim and Kim, 2007; Huang et al, 2010), so there is more ventilation in subway station. This characteristic means the subway station can achieve free cooling, and lower the energy consumption of HVAC system as a result. Thus, the two systems have their own benefits in different periods, because of which, they are suitable for different climate zones. In general concept, PSD system is more energy-effective in warmer area, so as PBD system in cooler area.

Recently, a combined system was proposed to take advantages of both PSD and PBD system (Hu and Lee,
2004). The innovative system has an adjustable vent on top of the platform door controlled by mechanic valve.

There are several related research on this Adjustable Ventilation Platform Doors (AVPD) System (Yang et al, 2015; Zhang et al, 2017). Studies have pointed out the fact that this AVPD system achieve better energy performance compared with the traditional PSD or PBD system. However, none of them considered the air leakage between tunnel and platform area when the adjustable vents closed (in this circumstance, the AVPD serves as PBD). According to the experimental research (Wang $\& \mathrm{Li}, 2017)$, the air leakage is a common phenomenon. In this sense, the existed studies on AVPD system over evaluated their energy saving potential, so it is necessary to conduct further research in this topic.

This paper applies STESS simulation to figure out the ventilation in both PSD and PBD systems. Based on the ventilation results, the energy saving potential in different climate zones is calculated. Last but not the least, the applicability of the AVPD system is discussed.

\section{Simulation method}

\section{Simulation software}

This research adopts Subway Thermal Environment Simulation Software (STESS) to simulate the ventilation in both PSD and PBD systems. STESS was a numerical tool developed by Tsinghua University in 1980s based on field tests and theoretical analyses. STESS can simulate the dynamic thermal environment of subway to guide the design and operation of environment control system (Wang \& Li, 2018).

\section{Simulation model}

The simulation model is created based on a real subway line located in Wuxi, a city in Jiangsu Province, China. There are 15 stations in the subway line, which is abstracted to node-branch model. Fig. 1 shows part of the simulation model for the limited space of the page. The branches include interval tunnel branch, platform tunnel branch, piston air shaft branch, platform door branch and inlets branch.

By adjusting the resistance value of the platform door branch using the listed data in Table 1, the ventilation in different situations can be acquired by STESS simulation, including in PSD and PBD systems. 


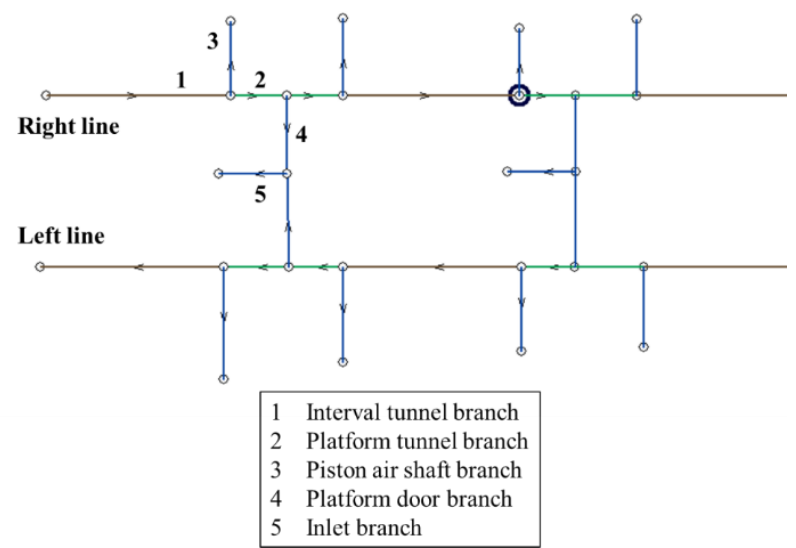

Figure 1: Scheme of the simulation model.

Table 1: Resistances of the platform door branch.

\begin{tabular}{|c|c|c|}
\hline Status of vents & Vent's area $\left.\mathbf{( m}^{\mathbf{2}}\right)$ & Resistance \\
\hline Closed (PBD) & 0.36 & 40.00 \\
\hline Semi-open & 12 & 2.00 \\
\hline Semi-open & 24 & 0.50 \\
\hline Semi-open & 36 & 0.22 \\
\hline Semi-open & 48 & 0.13 \\
\hline Open & 60 & 0.08 \\
\hline
\end{tabular}

\section{Simulation input data}

The major feature of the ventilation simulation in subways is the travelling pattern and its effect on ventilation. Therefore, the movement of trains should be taken into account.

The movement of trains is decribed in two aspects: traction curve and train departure density. Figure 2 shows a typical traction curve of the subway train. Figure 3 represents the train departure densities in phases when the passenger flow is high and low, respectively.

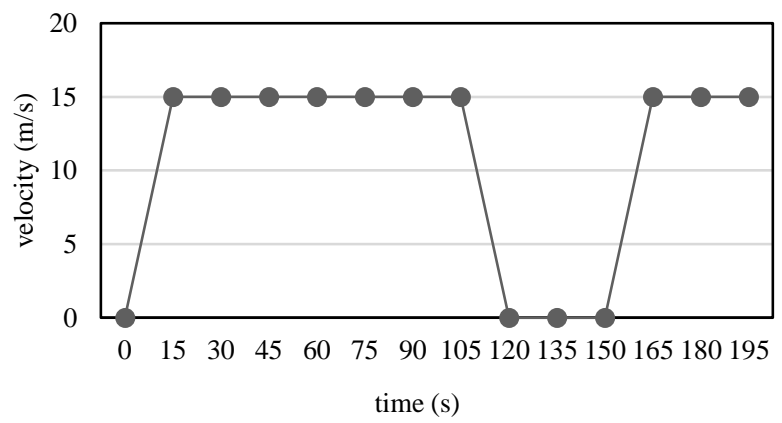

Figure 2: Typical traction curve of subway train.

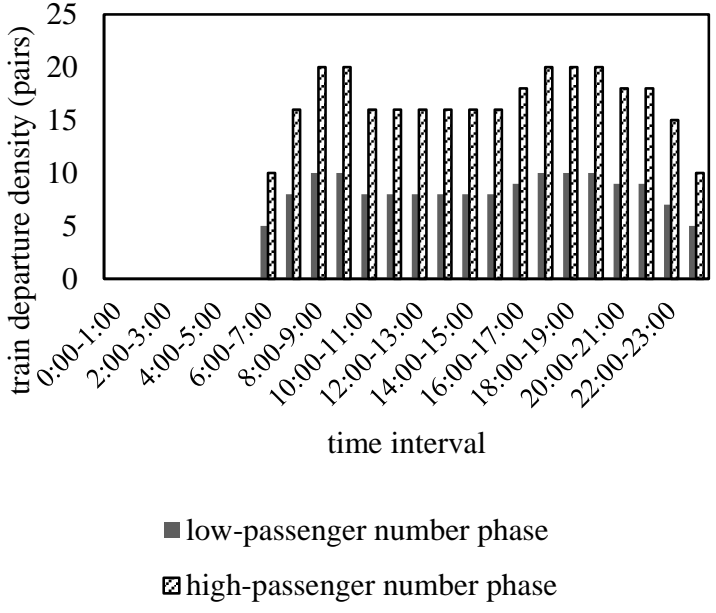

Figure 3: Train departure densities in different phases.

\section{Simulation results}

The adjustable ventilation platform door (AVPD) system is equipped with vents. By opening the vents, the PSD system transfers to PBD system. Figure 4 shows the simulation results of the airflow volume in both PBD and PSD system, which is fluctuating corresponding to the movement of trains.

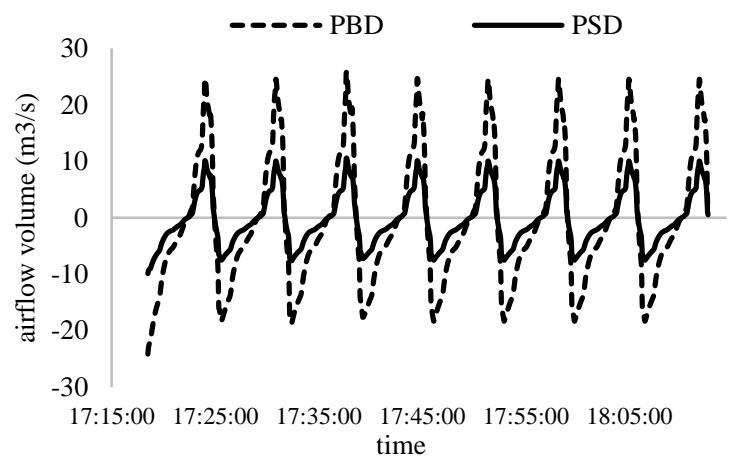

Figure 4: Ventilation in PBD and PSD system

However, the specific opening area of the vents and their effects on ventilation are not clear up to now. In this research, the ventilation volume in different vents area was calculated. Figure 5 shows the ventilation results under different vents' areas. From the results, the airflow volume increases with the increasing of vents' area, with the increasing rate decrease with the increasing vents' area. The reason of this feature is that the majority of airflow from the upper stream is to going into the downstream of subway tunnel, so the contribution of reducing the platform door branch's resistance is limited.

Moreover, when the vents' area reach $12 \mathrm{~m}^{2}$, the airflow volume can achieve $90 \%$ of the maximum level. When the vents' area reach $24 \mathrm{~m}^{2}$, the airflow volume can achieve $95 \%$ of the maximum level. Therefore, based on the economic consideration, the suitable area of the vents should be $12 \mathrm{~m}^{2}$. For a typical subway station, the length 
of platform is $120 \mathrm{~m}$, which means the width of vents is $10 \mathrm{~cm}$.

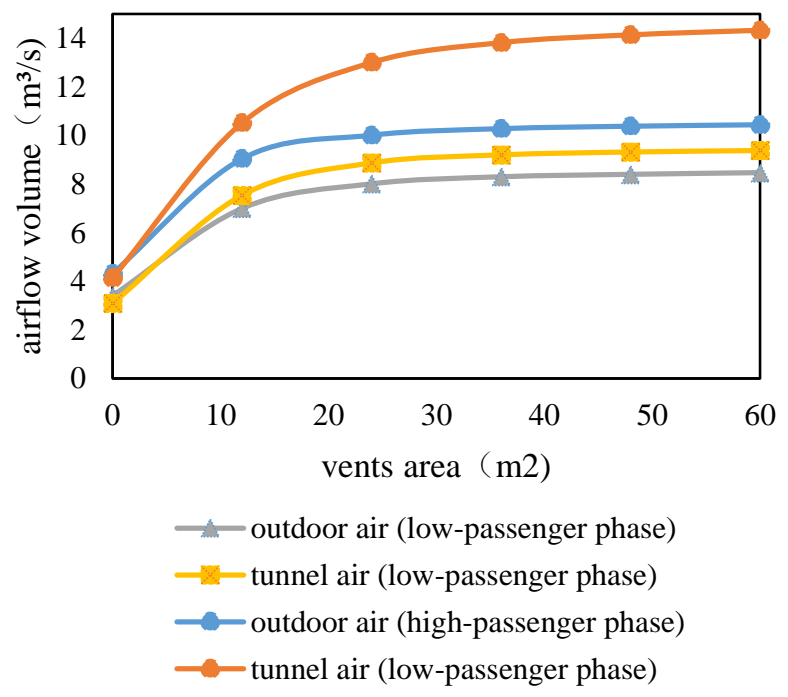

Figure 5: Ventilation in different vents area

\section{Energy analysis method}

This chapter mainly covers the calculation method of the energy consumption in subway station. The cooling load is divided into two separate parts, station load and ventilation load. The energy consumption of subway station HVAC system is determined by both the cooling load and the operation strategy of the devices.

\section{Cooling load calculation}

The heat released by the automatic gate machine, lights, illuminated advertising signs, lifts and elevators, other equipment, and passengers composes the station load. Table 2. lists the load of equipment according to their number and power listed in the design data.

The cooling load of passengers varies in both lowpassenger number and high-passenger number phases. The passenger flow in the low-passenger number phase was obtained from the measured data. While, in the highpassenger number phase, it was obtained from the designed passenger level determined by the scale and location of the subway station and other factors. Most of the standard subway stations are of similar scale in China with the averaged dimension of $180 \mathrm{~m}$ and $20 \mathrm{~m}$ in length and width, respectively. The passenger load curves in both low-passenger number and high-passenger number phases are shown in Figure 6. Therefore, the station load is almost invariant during the year, as it is determined by the equipment and passenger number.

Table 2: Components of station cooling load.

\begin{tabular}{|c|c|c|}
\hline Items & $\begin{array}{c}\text { Cooling load in } \\
\text { Low-passenger } \\
(\mathbf{k W})\end{array}$ & $\begin{array}{c}\text { Cooling load in } \\
\text { Low-passenger } \\
(\mathbf{k W})\end{array}$ \\
\hline
\end{tabular}

\begin{tabular}{|c|c|c|}
\hline $\begin{array}{c}\text { automatic gate } \\
\text { machine }\end{array}$ & 8.5 & 8.5 \\
\hline light & 28.4 & 28.4 \\
\hline $\begin{array}{c}\text { illuminated } \\
\text { advertising sign }\end{array}$ & 15.0 & 15.0 \\
\hline Lift \& elevator & 11.0 & 20.0 \\
\hline Other equipment & 6.2 & 6.2 \\
\hline
\end{tabular}

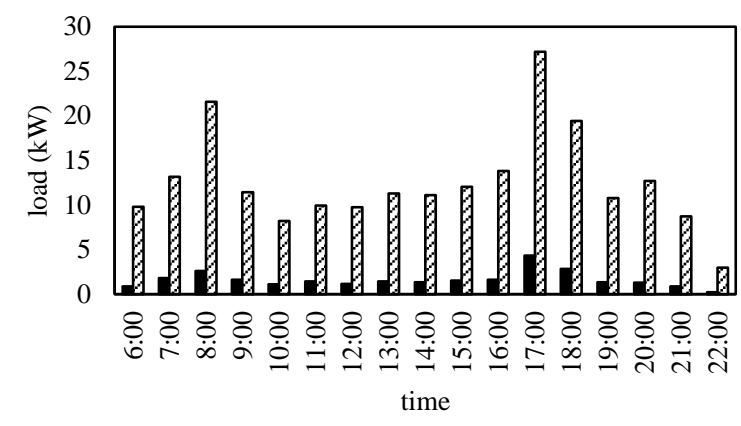

- passenger load in recent phase

$\mathrm{x}$ passenger load in future phase

\section{Figure 6: Typical passenger load curve during a day}

When the train travels in the tunnel, the piston effect causes the airflow from both tunnel and outdoors. The mass transfers of 'tunnel air-indoor air' and 'outdoor airindoor air' compose the ventilation load, which is changing from time to time with the airflow fluctuation.

There are two elements in ventilation load calculations, one is the enthalpy difference of the indoor and outdoor air, the other is the wind volume. The calculation equations of the ventilation load from the tunnel air and the outdoor air are given as Equation (1) and (2), respectively.

$Q_{\text {tunnel }}=\rho G_{\text {tunnel }}\left(i_{\text {tunnel }}-i_{\text {in }}\right)$

$Q_{\text {outdoor }}=\rho G_{\text {outdoor }}\left(i_{\text {out }}-i_{\text {in }}\right)$

\section{Energy consumption calculation}

Compared to the traditional platform door system like PSD and PBD system, the energy saving effect of the adjustable ventilation platform door (AVPD) system is based on its flexibility of ventilation. In summer, the vents are closed to reduce the ventilation cooling load from outdoor space. In transition seasons, the vents should open and the platform door serves as PBD, the ventilation is enhanced and the free-cooling effect is achieved through this way. Based on the above analysis, the primary research is to determine the switch condition of the close/open modes.

When the station cooling load can be handled by ventilation, the AVPD should open and become PBD. When additional mechanic ventilation is needed to enhance ventilation, it is not economic to open the vents. Because some cases in transition seasons, the averaged 
outdoor temperature is lower than the air temperature inside tunnel, if mechanic ventilation is applied, the fan will introduce the tunnel air rather than the outdoor air into the station area. Thus, when mechanic ventilation is used, the AVPD should closed and it serve as PSD. When the outdoor air is hotter than that inside the station, there is no doubt that the AVPD should closed, which is the same status as the previous situation.

After deciding the switching condition of the close/open modes in AVPD, the next step is to calculate the energy consumption of different systems by time intervals.

\section{Energy analysis results}

Based on the method described, the durations suitable to open the adjustable vents and its energy saving performance list in Table 3. Two typical climate zones including the Hot summer-Cold winter (HSCW) zone (ex: Shanghai) and the Hot summer-Warm winter (HSWW) zone (ex: Guangzhou) are analysed.

Table 3: Components of station cooling load.

\begin{tabular}{|c|c|c|c|}
\hline $\begin{array}{c}\text { Climate } \\
\text { zone }\end{array}$ & $\begin{array}{c}\text { Passenger } \\
\text { flow }\end{array}$ & $\begin{array}{c}\text { Vents-Open } \\
\text { period }\end{array}$ & $\begin{array}{c}\text { Energy } \\
\text { saving } \\
\text { (kWh/year) }\end{array}$ \\
\hline HSCW & Low & $\begin{array}{c}\text { Mid-Oct to } \\
\text { late-May }\end{array}$ & 11800 \\
\hline HSCW & High & $\begin{array}{c}\text { Late-Dec to } \\
\text { late-Feb }\end{array}$ & 2600 \\
\hline HSWW & Low & $\begin{array}{c}\text { Mid-Dec to } \\
\text { mid-March }\end{array}$ & 6700 \\
\hline HSWW & High & $/$ & $/$ \\
\hline
\end{tabular}

According to the energy analysis results, the AVPD system has the best energy saving performance when the passenger flow is relatively low. In HSCW climate zone, the annual energy saving potential is $11800 \mathrm{kWh}$; in HSWW climate zone, the annual energy saving potential is $6700 \mathrm{kWh}$. However, when the passage flow is high, which means the cooling load reaches a peak value, the AVPD system hardly show any energy saving advantages. In HSCW climate zone, only $2600 \mathrm{kWh}$ electricity saves annually. In HSWW climate zone, there shows no energy saving effect of this innovation system.

\section{Conclusion}

This paper uses STESS simulation to analyse the relationship between vents' area and ventilation volume. According to the simulation results, the ventilation volume increases with the vents' area increases, and then reaches a constant level. Based on the simulation result, the suitable vents' width is set to be $10 \mathrm{~cm}$.

Based on the ventilation simulation results, the energy saving potential was further analysed. In Hot summerCold winter (HSCW) climate zone, the energy consumption calculation shows that the subway station with low-passenger flow can use the AVDP system achieving economic profits. However, in subway station with high-passenger flow, where the cooling load is very high and the energy saving potential is quite limited, so the AVDP system is not recommended. In Hot summerWarm winter (HSWW) climate zone, both of the lowpassenger flow situation and the high-passenger flow situation are not suitable to use AVDP system, for its poor energy saving performance.

All in all, according to the energy performance analysis, the adjustable ventilation door system is only recommended in cities located in the Hot summer-Cold winter zone with low cooling load.

\section{Acknowledgement}

This work was supported by the National Natural Science Foundation of China (No. 51521005).

\section{References}

Chen, T.Y., Lee, Y.T., \& Hsu, C.C. (1998). Investigations of piston-effect and jet fan-effect in model vehicle tunnels. Journal of Wind Engineering and Industrial Aerodynamics, 73, 99-110.

Cross, D., Hughes, B., Ingham, D., \& Ma, L. (2017). Enhancing the piston effect in underground railway tunnels. Tunnelling and Underground Space Technology, 61, 71-81.

Kim, J.Y., \& Kim, K.Y. (2007). Experimental and numerical analyses of train-induced unsteady tunnel flow in subway. Tunnelling and Underground Space Technology, 22, 166-172.

Huang, Y.-d., Gao, W., \& Kim, C.-N. (2010). A numerical study of the train-induced unsteady airflow in a subway tunnel with natural ventilation ducts using the dynamic layering method. Journal of Hydrodynamics, Ser B, 22, 164-172.

Hu, S.-C., \& Lee, J.-H. (2004). Influence of platform screen doors on energy consumption of the environment control system of a mass rapid transit system: case study of the Taipei MRT system. Energy Conversion and Management, 45, 639-650.

Yang, Z., Su, X., Ma, F., Yu, L., \& Wang, H. (2015). An innovative environmental control system of subway. Journal of Wind Engineering and Industrial Aerodynamics, 147, 120-131.

Zhang, H., Cui, T., Liu, M., Zheng, W., Zhu, C., You, S., \& Zhang, Y. (2017). Energy performance investigation of an innovative environmental control system in subway station. Building and Environment, $126,68-81$

Wang Y and Li X (2017). Unorganized ventilation in subway stations with Platform Screen Doors. Building \& Environment, 125: 556-564

Wang Y and Li X (2018). STESS: Subway thermal environment simulation software. Sustainable Cities \& Society, 38: 98-1 
